DOI: https://doi.org/10.24867/12HZ06Savic

\title{
OPTIMIZACIJA ODREĐIVANJA HLORA U VODI POMOĆU FIBER OPTIČKIH SENZORA
}

\section{OPTIMIZATION OF CHLORINE DETERMINATION IN WATER USING FIBER OPTIC SENSORS}

\begin{abstract}
Nikola Savić, Boris Obrovski, Ivana Mihaj Oblast- INŽENJERSTVO ZAŠTITE ŽIVOTNE SREDINE

Kratak sadržaj- Sve veći razvoj ljudskog drušva $i$ industrije neminovno dovodi do prekomernog ispuštanja zagađujucih materija $u$ sve medijume životne sredine između ostalog i u akvatične sisteme. Iz tog razloga je od velike važnosti monitoring životne sredine. Postojeće metode ispitivanja imaju određene mane i ograničavajuće faktore primene. Iz tog razloga se sve više pažnje posvećuje razvoju novih, pouzdanih i preciznih uređaja kao što su optički senzori. Osnovni cilj rada jeste optimizacija odnosno primena kolorimetrijskog fiber optičkog senzora za određivanje hlora u uzorcima vode.
\end{abstract}

Ključne reči: Senzori na bazi optičkih vlakna, monitoring akvatičnih sistema, hlor.

\begin{abstract}
The ever-increasing development of society and industry inevitably causes excessive release of pollutants into all environmental media, including aquatic systems. Present-day methods of examination have their drawbacks and limiting factors of application. Because of this, more and more attention is being given to the development of new, reliable and accurate devices such as optical sensors. The main goal of the thesis is optimization and application of colorimetric fiber-optic sensors for chlorine detection in water samples.
\end{abstract}

Keywords: Fiber optic sensor, monitoring of aquatic systems, chlorine

\section{UVOD}

Sve veći broj stanovnika kao i rast standarda samih ljudi, dovelo je do mnogobrojnih negativnih efekata na životnu sredinu, kao što su prekomerno ispuštanje zagađujućih materija u životnu sredinu kao i generisanje i stvaranje novih zagađujućih supstanci sa potencijalno negativnim uticajem na zdravlje ljudi i svih živih organizama.

Imajući u vidu sve veće zagađenje životne sredine, monitoring kvaliteta različitih vodenih medijuma predstavlja veoma važan deo u upravljanju sistemom zaštite životne sredine.

\footnotetext{
NAPOMENA:

Ovaj rad proistekao je iz master rada čiji mentor je bila vanr. prof. dr Ivana Mihajlović.
}

Težnja ka pronalaženju novih tehnologija, koje daju kontinualne, in-situ prostorne i vremenske informacije o trenutnom stanju ispitivanog vodnog tela, proizašla je iz mnogobrojnih ograničavajućih faktora konvencionalnih laboratorijskih metoda. Pronalazak lasera doveo je do razvoja fiber optičkih senzorskih metoda koje su kasnije razvijene i prilagođene za upotrebu u praćenju kvaliteta životne sredine.

$\mathrm{Za}$ razliku od konvencionalnih metoda, koje su kompleksne, zahtevaju primenu različitih hemikalija, zahtevaju komplikovanu pripremu uzoraka za anlizu, skupe uređaje, mogućnost grešaka analitičara, primena novih tehnologija, konkretno metoda na bazi optičkih senzora imaju mnogobrojne prednosti. Neke od njih su: očitavanje trenutnih koncentracionih nivoa analiziranih parametara, jednostavnost pripreme uzoraka, jeftine komponente koje se koriste za njihovu izradu, male dimenzije uređaja, mogućnost primene na nepristupačnim i opasnim terenima i mnoge druge.

Baš te prednosti dovele su do sve većih istraživanja iz oblasti primene optičkih senzora, kao i same primene i zamene konvencionalnih laboratorijskih metoda, metodama na bazi senzora.

Upravo ove prednosti su dovele do sve veće primene fiber optičkih senzora za merenje koncentracija različitih fizičko-hemijskih parametara u vodenim uzorcima.

\section{STRUKTURA OPTIČKOG VLAKNA}

Sastavni deo fiber optičkog senzora je optičko vlakno čiji rad se zasniva na višestrukoj totalnoj refleksiji. U optičkom vlaknu svetlosni zraci su "zarobljeni" efektom višestruke totalne refleksije i ne mogu da izađu izvan vlakna (kabla), što omogućava prenošenje signala na veliku udaljenost. Optičko vlakno je sačinjeno od tri dela :jezgra, obloge i prevlake. Osnovna struktura je prikazana na slici 1 .

Jezgro je cilindrična šipka od dielektričnog materijala $\mathrm{i}$ uglavnom je izrađena od stakla ili polimetilmetakrilata. Svetlost se širi uglavnom duž jezgra vlakna. Osnovna funkcija obloge jeste smanjenje gubitka svetlosti iz jezgra u okolinu, smanjenje raspršivanja na površini jezgra, zaštita vlakna od apsorpcije površinskih kontaminanata kao i dodavanje dodatne mehaničke čvrstoće. Prevlaka ili pufer je sloj materijala koji se koristi da zaštiti optičko vlakno od eventualnog fizičkog oštećenja. Uglavnom materijal koji se koristi za izradu prevlake je plastika. Obloga kabla jeste elastični deo optičkog vlakna čija je osnovna funkcija sprečavanje stvaranja ogrebotina. 


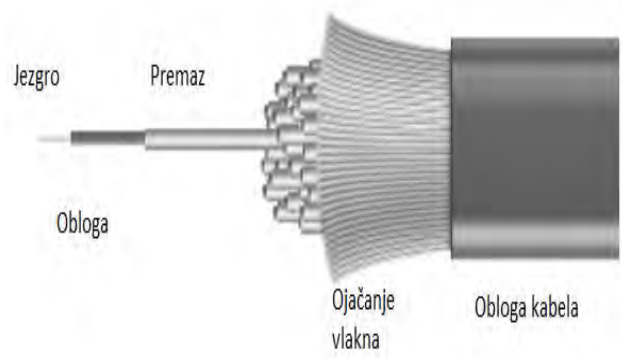

Slika 1: Osnovna struktura optičkog vlakna [1]

Danas se za izradu optičkih vlakna mogu koriste polimeri, najčešće polimetilmetakrilat (PMMA, poznatiji kao pleksiglas) čija upotreba redukuje troškove. Dimenzije prečnika polimernih optičkih vlakana (POV) se kreću u rasponu od $100 \mu \mathrm{m}$ do $300 \mu \mathrm{m}$. Mnogobrojne su prednosti POV u odnosu na vlakna napravljenih od stakla, te se iz tog razloga mnogo češće upotrebljavaju u praksi.

Princip kretanja svetlosti duž vlakna zasnovan je na "potpunom unutrašnjem odrazu".

Ugao pod kojim se odvija totalna unutrašnja refleksija naziva se kritičnim uglom upada.

Pod bilo kojim većim uglom od kritičnog ugla, svetlost se potpuno reflektuje nazad u stakleni medijum što se može i videti na slici 2 .

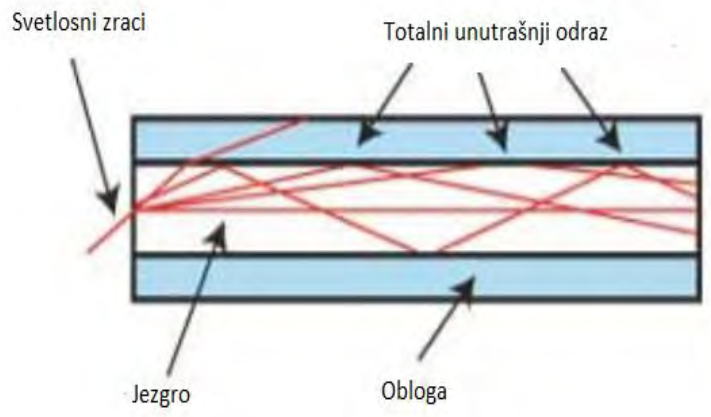

Slika 2: Totalni unutrašnji odraz u optičkom vlaknu [1]

\section{UV-VIS SPEKTROFOTOMETRIJA}

Spektrofotometar je uređaj za analizu spektra elektromagnetskog zračenja. Sastoji se od izvora zračenja, monohromatora i detektora.

Većina spektroskopskih uređaja je sačinjeno od sledećih osnovnih delova:

- stabilnog izvora energije zračenja,

- selektora talasnih dužina koji omogućava izdvajanje određenog talasnog područja,

- jednog ili više postolja za uzorak,

- detektora zračenja ili konvertora energije zračenja u merljiv signal,

- procesora signala i uređaja za njegovo učitavanje.

Spektroskopski uređaji zahtevaju konstantan i dovoljno snažan izvora zračenja koji omogućava jednostavnu detekciju i merenje.

Zbog toga se često uz izvore zračenja upotrebljavaju regulatori napona, kako bi se sprečili negativni uticaju koji nastaju pri promeni napona izvora zračenja.

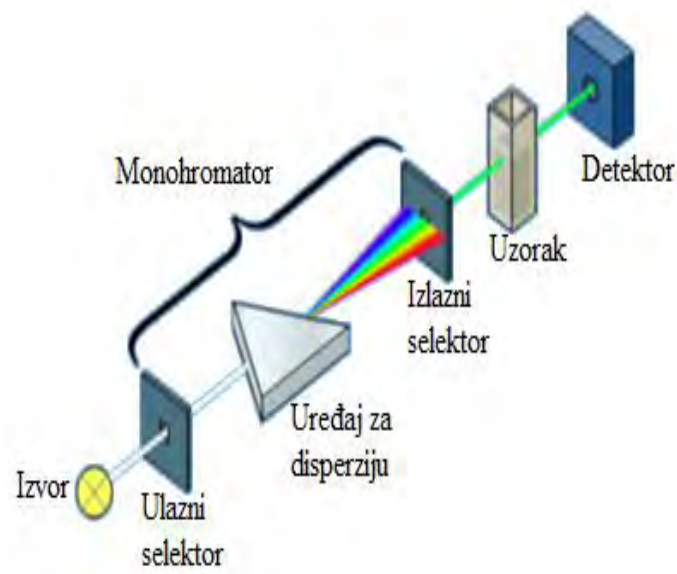

Slika 3: Princip rada UV-VIS spektrofotometra [2]

Prema tipu spektra koji emituju izvori zračenja se dele na: - $\quad$ izvore koje emituju kontinualan spektar, kontinualni spektar je okarakterisan neprekidnom raspodelom energije $u$ širokom intervalu frekvencije bez oštrih linija,

- $\quad$ izvore koji emituju diskontinualan spektar, traka diskontinualnog spektra se sastoji od niza odvojenih, manje ili više oštrih linija i traka.

\section{PRINCIP RADA KOLORIMETRIJSKOG FIBER- OPTIČKOG SENZORA}

Metoda kolorimetrijskog fiber-optičkog senzora (KFOS) odabrana je za merenje koncentracija fizičko-hemijskih parametara u vodenim sistemima. KFOS ima višestruku primenu. Baš iz tog razloga, konkretno u ovom slučaju je odabran za određivanje koncentracija hlora u uzorcima vode. KFOS se sastoji od predajnog i prijemnog dela. Predajni deo se sastoji od tri LED diode koje emituju crvenu, zelenu (G) i plavu (B) komponentu vidlivog dela spektra. Primenjeni senzor određuje boju na osnovu principa aditivnog mešanja boja i kao rezultat dobija se boja tečnosti koja može da se izrazi u RGB modelu boja. Talasne dužine za R, G i B LED diode su locirane na $\lambda_{R}=634 \mathrm{~nm}, \quad \lambda_{G}=516 \mathrm{~nm}, \quad \lambda_{B}=466 \mathrm{~nm} . \quad$ Kada svetlost prođe kroz rastvor, određene talasne dužine bivaju apsorbovane $\mathrm{u}$ zavisnosti od boje rastvora koji zavisi od vrste i koncentracije analizirane supstance $u$ njemu. Blok dijagram korišćenog senzora dat je na slici 4

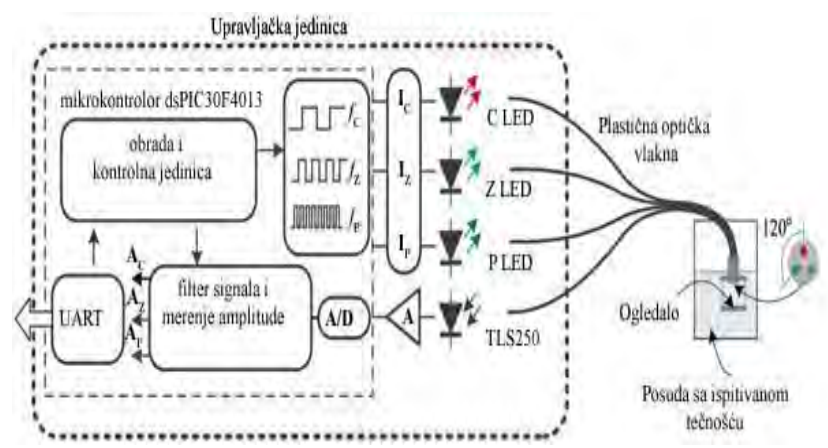

Slika 4: Blok dijagram primenjenog senzora boje [3]

Za izradu uređaja su upotrebljena plastična optička vlakna prečnika $1 \mathrm{~mm}$. 
Četiri optička vlakna su povezana u jedan snop ispod koga je smešteno ogledalo. Svetlost određene talasne dužine je sprovedena $u$ tri predajna plastična optička vlakna koja vode crvenu, zelenu i plavu komponentu do ispitivanog rastvora.

Centralno prijemno optičko vlakno prikuplja deo reflektovane svetlosti odbijene od ogledala i vodi je do fotodetektora TSL250.

Fotodetektor TSL250 je prvi element prijemnog dela koji detektuje reflektovanu svetlost i konvertuje je $u$ odgovarajći naponski signal. TSL250 konvertuje optički signal u električni.

Signal iz fotodetektora je pojačan i sproveden do 12 bitnog A/D pretvarača. Promene u intenzitetu svetlosti se konvertuju sa A/D pretvaračem u digitalni oblik.

Nakon A/D konverzije sprovodi se demultipleksiranje signala primenom filtera. Filteri su upotrebljeni kao Batevortovi filtri 8. reda. Nakon demultipleksiranja na mikrokontroleru određuje se amplituda za svaki signal i dobijene vrednosti se prosleđuju softveru na računaru preko serijske komunikacije.

KFOS sadrži displej osetljiv na dodir (grafički displej) pomoću koga je moguće podešavati način rada uređaja i služi za komunikaciju uređaja sa korisnikom.

\section{REZULTATI I DISKUSIJA}

Uzorci neophodni za analizu prikupljeni su sa dve lokacije:

- leva strana reke Dunav kod Novog Sada,

- zatvoreni bazen spens, čija je osnovna namena održavanje sportskih aktivnosti.

Svi prikupljeni uzorci su skladišteni i transportovani do akreditovane laboratorije na propisan nači, gde su vršene sve potrebne analize.

Uzorci su ispitivani standardnom UV-VIS spektrofotometrijskom metodom i KFOS nakon čega je vršeno poređenje dobijenih vrednosti. Opseg KFOS uređaja za ukupan hlor je od 0 do 2,20 mg/L, dok je za standardnu metodu koja se koristi na spektrofotometru od 0,02 do 2,00 mg/L.

Rezultati koncentracija ukupnog hlora površinske vode Dunava merene UV-VIS i KFOS dati su u tabeli 1.

Tabela 1 Koncentracija ukupnog hlora površinske vode Dunava merene UV-VIS i KFOS

\begin{tabular}{|c|c|c|c|}
\hline Parametri & $\begin{array}{c}\text { Spektrofotometar } \\
{[\mathrm{mg} / \mathrm{L}]}\end{array}$ & $\begin{array}{c}\text { Senzor } \\
{[\mathrm{mg} / \mathrm{L}]}\end{array}$ & $\begin{array}{c}\text { Relativno } \\
\text { odstupanje } \\
{[\%]}\end{array}$ \\
\hline $\begin{array}{c}\text { Ukupni } \\
\text { hlor }\end{array}$ & 0,484 & 0,514 & $\mathbf{6 , 2 0}$ \\
\hline
\end{tabular}

$\mathrm{Na}$ osnovu rezultata može se zaključiti da je relativno odstupanje ove dve metode u dozvoljenim granicama koje iznosi manje od $10 \%$.

Najvažniji parametar koji se prati u uzorcima vode zatvorenih bazena jeste hlor. Hlor se koristi kao dezinfekciono sredstvo i veoma je važno njegovo praćenje jer pri reakciji sa organskim i neorganskim materijama, koje se mogu naći u vodama rekreacionih bazena može doći do stvaranje različitih toksičnih jedinjenja.

Kada je reč o uzorcima vode rekreacionog bazena, merene su koncentracije za ukupan i rezidualan hlor.
Individualne kalibracione krive za ukupan i rezidualan hlor su date na slikama 5-6.

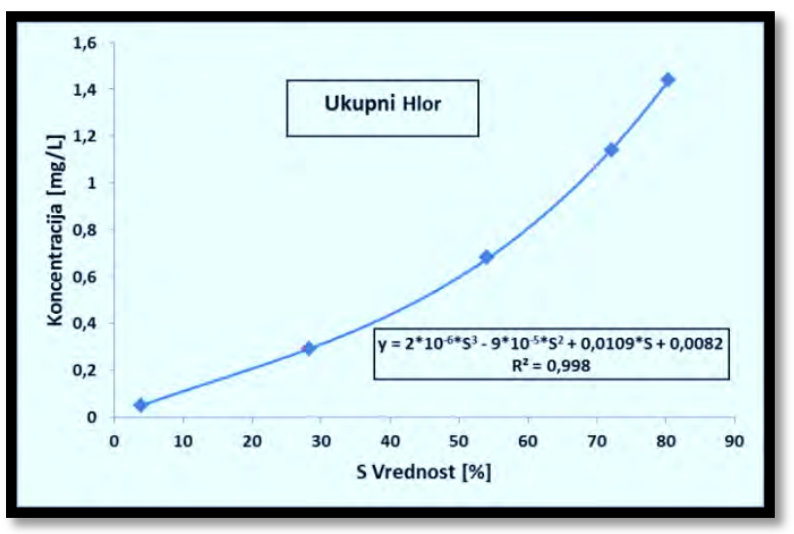

Slika 5 Kalibraciona kriva za ukupan hlor

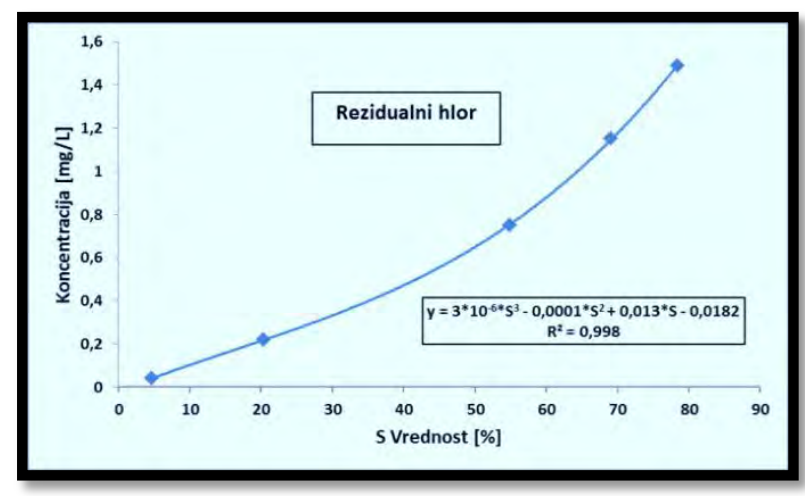

Slika 6 Kalibraciona kriva za rezidualni hlor

Koncentracija rezidualnog hlora $\mathrm{u}$ uzorcima bazenske vode je niska, zbog čega su uzorci spajkovani poznatim standardnim rastvorom kako bi se osetljivost KFOS povećala. Rastvor za spajkovanje uzoraka sastoji se od kaliju permanganata, što dovodi do povećanja boje u uzorku a samim tim i očitavanje povišenih koncentracija rezidualnog hlora. Vrednosti spajka kao i „,Recovery“ za rezidualni i ukupni hlor dati su u tabelama 2-3.

Tabela 2 Tačnost merenja UV-VIS spektrofotometra za rezidualni hlor

\begin{tabular}{|c|c|c|c|}
\hline Broj merenja & $\begin{array}{c}\text { Koncentracij } \\
\text { a } \\
\text { sakupljenog } \\
\text { uzorka (UV- } \\
\text { VIS } \\
\text { spektrofotom } \\
\text { etar) [mg/L] }\end{array}$ & $\begin{array}{c}\text { Koncentracij } \\
\text { a } \\
\text { spajkovanog } \\
\text { uzorka (UV- } \\
\text { VIS } \\
\text { spektrofotom } \\
\text { etar) [mg/L] }\end{array}$ & $\begin{array}{c}\text { "Recovery" } \\
\text { (UV-VIS } \\
\text { spektrofotom } \\
\text { etar) [\%] }\end{array}$ \\
\hline 1 & 0,19 & 0,65 & 94,2 \\
\hline 2 & 0,11 & 0,94 & 84,7 \\
\hline 3 & 0,08 & 0,86 & 79,6 \\
\hline 4 & 0,13 & 0,95 & 84 \\
\hline 5 & 0,23 & 1,03 & 83,7 \\
\hline 6 & 0,15 & 0,9 & 78,2 \\
\hline 7 & 0,23 & 0,98 & 79,6 \\
\hline 8 & 0,12 & 0,89 & 79,4 \\
\hline 9 & 0,16 & 0,98 & 84,4 \\
\hline
\end{tabular}

Vrednost „Recovery“ za rezidualni hlor uzoraka bazenske vode analizirani sa UV-VIS spektrofotometriskom metodom su u intervalu od 78,2 \% do 94,2 \%. Dok je vrednost „Recovery“ za rezidualni hlor uzoraka bazenske 
vode analiziranih sa KFOS $\mathrm{u}$ intervalu od $87,6 \%$ do $100,7 \%$.

Ako se vrednosti „Recovery“ za svako pojedinačno merenje uporede, može se videti da su vrednosti ,Recovery“ za uzorke analiziranane sa KFOS manje od vrednosti „Recovery“ za uzorke analizirane sa UV-VIS spektrofotometrom. Što govori da je tačnost kolorimetrijske senzorske metode veća od tačnosti standardne laboratorijske metode.

Tabela 3 : Tačnost merenja KFOS za rezidualni hlor

\begin{tabular}{|c|c|c|c|}
\hline Broj merenja & $\begin{array}{c}\text { Koncentracij } \\
\text { a } \\
\text { sakupljenog } \\
\text { uzorka } \\
\text { (KFOS) } \\
\text { [mg/L] }\end{array}$ & $\begin{array}{c}\text { Koncentracij } \\
\text { a } \\
\text { spajkovanog } \\
\text { uzorka } \\
\text { (KFOS) } \\
\text { [mg/L] }\end{array}$ & $\begin{array}{l}\text { "Recovery" } \\
\text { (KFOS) [\%] }\end{array}$ \\
\hline 1 & 0.211 & 0.694 & 97.6 \\
\hline 2 & 0.069 & 1.076 & 100.7 \\
\hline 3 & 0.079 & 0.973 & 90.1 \\
\hline 4 & 0.139 & 0.998 & 87,6 \\
\hline 5 & 0.261 & 1.262 & 100.1 \\
\hline 6 & 0.177 & 1.117 & 94.9 \\
\hline 7 & 0.245 & 1.217 & 97.7 \\
\hline 8 & 0.163 & 1.159 & 99.6 \\
\hline 9 & 0.220 & 1.187 & 97.3 \\
\hline
\end{tabular}

\section{ZAKLJUČNO RAZMATRANJE}

Konkretno, u ovom radu je razmatrana primena kolorimetrijskog fiber-optičkog senzora (KFOS) za određivanje koncentracionog nivoa hlora u uzorcima vode. $\mathrm{Na}$ osnovu vrednosti dobijenih UV-VIS spektrofotometrijskom metodom i KFOS kao i poređenjem istih, zaključeno je da je KFOS pokazao najbolje rezultate za merenje ukupnog i rezidualngo hlora u uzorcima vode rekreacionig bazena. Apsolutno odstupanje vrednosti za ukupan hlor je 0,008 do $0,071 \mathrm{mg} / \mathrm{L}$ dok je za rezidualni hlor u rasponu od $0,001 \mathrm{mg} / \mathrm{L}$ do $0,031 \mathrm{mg} / \mathrm{L}$.

Takođe vrednost „Recovery“ za spajkovane uzorke dobijene KFOS je bolja od onih dobijenih UV-VIS spektrofotometrom. Na osnovu rezultata zaključeno je da KFOS potvrđuje primenu za merenje ukupnog i rezidualnog hlora u uzorcima vode.

Imajući u vidu veliku oksidacionu sposobnost hlora kao i veliki uticaj drugih faktora na reaktivnost hlora, od velike je važnosti nastavak poboljšavanja karakteristika senzora.

\section{LITERATURA}

[1] Alan Kersey, Anthony Dandridge: Fiber optic sensors and their applications

[2] С. Ментус, Љ. Дамјановић, Физичкохемијска анализа, Универзитет у Београду Факултет за физичку хемију, Београд 2015.

[3] Todorović M, Đurđević P, Antonijević V. (1993). Optičke metode instrumentalne analize, Hemijski fakultet, Beograd.

\section{Kratka biografija :}

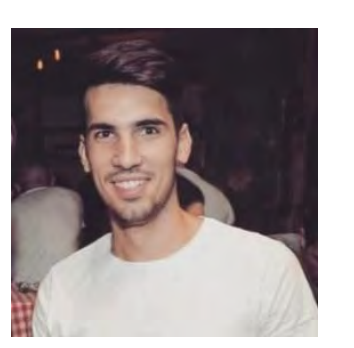

Nikola Savić je rođen 1995. godine u Beogradu. Osnovne studije je završio 2019. godine na Fakultetu tehničkih nauka u Novom Sadu iz oblasti inženjerstva zaštite životne sredine.

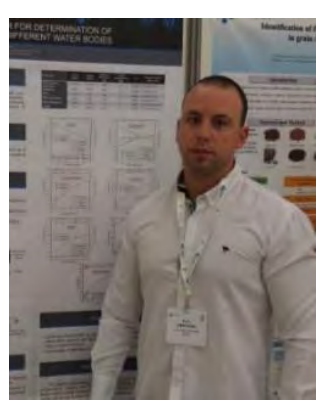

Boris Obrovski je odbranio 2020. godine doktorsku disertaciju na Fakultetu tehničkih nauka iz oblasti Inženjerstva zaštite životne sredine. Trenutno je zaposlen na Fakultetu tehničkih nauka u zvanju istraživač saradnik.

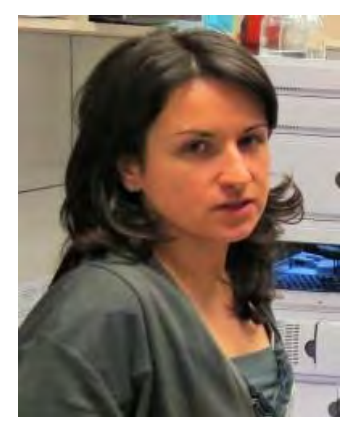

Ivana Mihajlović rođena je u Boru 1984. godine. Od 2020. god. je vanredni profesor na Fakultetu tehničkih nauka u Novom Sadu, na katedri za Inženjerstvo zaštite životne sredine. 